\title{
Degradation of dye solution by an activated carbon fiber electrode electrolysis system
}

\author{
Zhemin Shen $^{\mathrm{a}, *}$, Wenhua Wang ${ }^{\mathrm{b}}$, Jinping Jia ${ }^{\mathrm{b}}$, \\ Jianchang Ye $^{\mathrm{b}}$, Xue Feng ${ }^{\mathrm{b}}$, An Peng ${ }^{\mathrm{a}}$ \\ a State Key Laboratory of Environmental Aquatic Chemistry, Research Center for Eco-environmental Sciences, \\ Chinese Academy of Sciences, Beijing 100085, PR China \\ ${ }^{\mathrm{b}}$ School of Environmental Science and Engineering, Shanghai Jiaotong University, Shanghai 200240, PR China
}

Received 18 August 2000; received in revised form 20 February 2001; accepted 1 March 2001

\begin{abstract}
Degradation of 29 dyes by means of an activated carbon fiber (ACF) electrode electrolysis system was performed successfully. Almost all dye solutions tested were decolorized effectively in this ACF electrolysis process. Internal relationships between treatment mechanisms and chemical composition of the dye have been discussed in this paper. Generally, it is shown that higher solubility leads to greater degradation in the process. Dyes with many $-\mathrm{SO}_{3}{ }^{-}, \mathrm{COO}^{-},-\mathrm{SO}_{2} \mathrm{NH}_{2},-\mathrm{OH}$, hydrophilic groups, and azo linkages are susceptible to reduction. However, dyes with many $-\mathrm{C}=\mathrm{O},-\mathrm{NH}-$ and aromatic groups, and hydrophobic groups, tend to be adsorbed. For dyes with $-\mathrm{SO}_{3}{ }^{-},-\mathrm{COOH}$ and -OH groups, if their molecules linearly spread in solution and have a significant tendency to form colloids by hydrogenous bonding, they also tend to be adsorbed and flocculated. Typical dynamic electrolysis of dye Acid Red B, Vat Blue BO and Disperse Red E-4B shows how the two major mechanisms, degradation and adsorption, act differently during treatment. Reduction occurs evenly during treatment. During the dominant adsorption process, after certain amount of iron is generated, colloid precipitation occurs and TOC and color are rapidly removed. () 2001 Elsevier Science B.V. All rights reserved.
\end{abstract}

Keywords: Dye; Electrode; Electrolysis; Wastewater; Treatment

\section{Introduction}

Dye-synthesizing wastewater and textile wastewater are two types of poorly treated wastewater that contain organic dyes. These wastewater are characterized by strong color, highly fluctuating $\mathrm{pH}$, high COD and bio-toxicity [1,2].

\footnotetext{
* Corresponding author. Tel.: +86-10-62849141; fax: +86-10-62923543.

E-mail address: shenzhemin@sina.com (Z. Shen).
} 
There are many kinds of dye on the market. In view of their chemical structures, dyes can be characterized as an azo dye, anthraquinone dye, heterocyclic dye, etc. Dyes can also be characterized according to their application method into vat dye, reactive dye, direct dye, acid dye, dispersed dye, etc.

Because of the variability of organic dyes and the resultant waste solution, wastewater containing dyes is difficult to treat using traditional methods. Many kinds of bio-refractory and soluble dyes render traditional bio-chemical process and coagulant process inadequate. The cost of treatment by active carbon adsorption is high. Ozone and hypochlorite oxidation are efficient decolorization methods, but they are not desirable because of the high cost for equipment, and operating costs and the secondary pollution arising from the residual chlorine [3]. A direct electrochemical method has been examined to address these problems.

Recent progress in treatment of these kinds of wastewater has led to the development of electrochemical processes [4,5]. Because electrolysis often consumes much energy, especially in dilute wastewater treatment processes, new methods and materials have been proposed [6,7]. Three-dimensional electrodes, one of the methods that can be used to reduce the energy requirement of electrolysis, can greatly enhance the surface area of electrode, can regulate electric current density, and can reduce side-effects. Consequently, it can greatly enhance the energy efficiency of the reaction. This method of treatment has been utilized previously [8,9].

Activated carbon fiber (ACF), namely activated carbon felt is a type of three-dimensional electrode, whose surface area can reach $1000 \mathrm{~m}^{2} \mathrm{~g}^{-1}$ [10]. However, there are many functional groups on its surface, such as $=\mathrm{C}=\mathrm{O}$. This material can greatly adsorb significant amounts of pollutants, such as trihalomethanes, bromoform, atrazine, dyes and natural organic matters [11-15] or react with them chemically or physically [16,17]. It is also reported that $\mathrm{pH}$ value and temperature has no significant effect on its adsorptive capacity [13]. Exprosito et al. [18] used $1 \mathrm{~cm}$ thick carbon felt as the cathode to reduce energy consumption in the removal of lead from industrial effluents. Okochi et al. and Matsunaga et al. [19,20] have constructed novel electrochemical reactors employing activated carbon fibers for disinfecting bacteria in drinking water. Our group's earlier study showed that electrochemical process with an ACF cathode and a Fe anode can efficiently decolorize wastewater [21]. The following half reactions occur at the electrodes:

Fe anode (oxidation)

$$
\mathrm{Fe} \rightarrow \mathrm{Fe}^{2+}+2 \mathrm{e}^{-}
$$

ACF cathode (reduction)

$$
2 \mathrm{H}_{2} \mathrm{O}+2 \mathrm{e}^{-} \rightarrow \mathrm{H}_{2}(\mathrm{~g})+2 \mathrm{OH}^{-}
$$

Overall

$$
\mathrm{Fe}+2 \mathrm{H}_{2} \mathrm{O} \rightarrow \mathrm{Fe}(\mathrm{OH})_{2}(\mathrm{~s})+\mathrm{H}_{2}
$$

The mechanism by which this system effects color removal is not completely understood, and may vary for different classes of dye [22]. Karunratne and Lemley [22] has decolorized solutions of Acid Red 337 (azo) and Acid Blue 40 (anthroquinone) with a similar 
system and investigated its mechanism of operation using a Hewlett-Packard model 1090A liquid chromatograph with diode-array detection. The peaks of high performance liquid chromatography (HPLC) indicated different decolorization mechanisms between the two dyes studied. It is indicated that both degradation and adsorption are involved in color removal with azo dyes but that adsorption is the predominant mechanism of dye removal with anthrequionoe dyes.

To confirm these initial conclusions, 29 kinds of dye were tested in ACF electrode system. This research program also analyzed the reaction data in order to ascertain the relationship between efficiency and dye chemical structure and type, a process which might give scientific guidance for treating dye wastewater.

\section{Materials and methods}

\subsection{Dye}

About 29 kinds of dye, numbered from 1 to 29, were studied. A serial number uniformly stands for a certain experimentally used dye in this paper. Their experimental serial numbers, chemical structures, and commercial index number (CI no.) are listed in Table 1.

\subsection{Electrolysis apparatus}

The ACF electrolysis experiment apparatus consisted of an ACF electrode, Fe electrode, and a dc power source.

\subsection{Analytical measurement}

A total organic carbon analyzer (TOC-500, Shimadzu, Japan) was used to measure the concentration of organic carbon in solution. The color of solutions was analyzed using a Du-650 spectrophotometer (Du-650, Beckman, USA). Each dye solution was scanned and its maximum absorbency visible wavelength determined. TOC and color removal ratios (\%) were calculated as follows

$$
R_{\mathrm{TOC}}=\frac{\left(\mathrm{TOC}_{0}-\mathrm{TOC}\right)}{\mathrm{TOC}_{0}} \times 100 \%
$$

where $\mathrm{TOC}_{0}$ is the TOC value before electrolysis; TOC the TOC value after electrolysis.

$$
R_{\text {color }}=\frac{\left(\mathrm{ABS}_{0}^{\mathrm{M}}-\mathrm{ABS}^{\mathrm{M}}\right)}{\mathrm{ABS}_{0}^{\mathrm{M}}} \times 100 \%
$$

where, $\mathrm{ABS}^{\mathrm{M}}$ is the average of absorbency values at its maximum absorbency visible wavelength; $\mathrm{ABS}_{0}^{\mathrm{M}}$ the $\mathrm{ABS}^{\mathrm{M}}$ value before electrolysis; $\mathrm{ABS}^{\mathrm{M}}$ the $\mathrm{ABS}^{\mathrm{M}}$ value after electrolysis. 
Table 1

Serial numbers, chemical structures, types and CI no. of the dye utilized ${ }^{\mathrm{a}}$

\begin{tabular}{|c|c|c|c|c|c|c|}
\hline $\begin{array}{l}\text { Serial } \\
\text { number }\end{array}$ & Dye & Solubility & Chemical structure & Type & CI no. & TOC $/$ color $^{\mathrm{a}}$ \\
\hline 1 & Acid Red B & Excellent $\left(>30 \mathrm{~g} \mathrm{l}^{-1}\right)$ & Single-azo & Acid & $\begin{array}{l}\text { Acid Red } 14(14720) ; \text { CI } \\
\text { Food Red } 3(14720)\end{array}$ & 0.3215 \\
\hline 3 & Acid Red G & Excellent $\left(>30 \mathrm{~g}^{-1}\right)$ & Single-azo & Acid & CI Acid Red 1 (18050) & 0.3776 \\
\hline 4 & Reactive Flavine K-4G & Good $\left(3-30 \mathrm{gl}^{-1}\right)$ & Single-azo & Reactive & CI Reactive Yellow 18 & 0.3778 \\
\hline 5 & Neutral Grey 2BL & Excellent $\left(>30 \mathrm{gl}^{-1}\right)$ & Single-azo & Neutral & CI Acid Black 60 (181165) & 0.4073 \\
\hline 6 & Direct Green B & Excellent $\left(>30 \mathrm{gl}^{-1}\right)$ & Multi-azo & Direct & CI Direct Green 6 (30295) & 0.4128 \\
\hline 9 & Reactive Brilliant Red KM-8B & Excellent $\left(>30 \mathrm{gl}^{-1}\right)$ & Single-azo & Reactive & & 0.4658 \\
\hline 10 & Acid Blue BGA & Excellent $\left(>30 \mathrm{~g} \mathrm{l}^{-1}\right)$ & Triaryl methane & Acid & & 04686 \\
\hline 11 & Shangda Sulfur Black BN & $\operatorname{Bad}\left(<3 \mathrm{gl}^{-1}\right)$ & Sulfide & Sulfur & CI Sulfur Black (53185) & 0.5313 \\
\hline 12 & Acid Navy Blue GGR & Excellent $\left(>30 \mathrm{~g}^{-1}\right)$ & Diazo & Acid & & 0.5333 \\
\hline 13 & Reactive Brilliant Red K-2G & Excellent $\left(>30 \mathrm{gl}^{-1}\right)$ & Single-azo & Reactive & CI Reactive Red 15 & 0.5460 \\
\hline 14 & Cationic Red 2GL & Excellent $\left(>30 \mathrm{~g} \mathrm{l}^{-1}\right)$ & Heterocyclic & Cationic & CI Basic Red 29 (11460) & 0.5600 \\
\hline 19 & Reactive Brilliant Blue X-BR & Excellent $\left(>30 \mathrm{gl}^{-1}\right)$ & Anthraquinone & Reactive & CI Reactive Blue 4 (61205) & 0.6073 \\
\hline 20 & Direct Orange $\mathrm{S}$ & Good $(3-30 \mathrm{gl})$ & Double-azo & Direct & CI Direct Orange 26 (29150) & 0.6100 \\
\hline 21 & Vat Red F3B & $\operatorname{Bad}\left(<3 \mathrm{gl}^{-1}\right)$ & Anthraquinone & Vat & CI Vat Red 31 & 0.6295 \\
\hline 22 & Dispersed Red E-4B & $\operatorname{Bad}\left(<3 \mathrm{gl}^{-1}\right)$ & Single-azo & Disperse & CI Dispersed Red 60 (60756) & 0.6462 \\
\hline 23 & Vat Brilliant Violet RR & $\operatorname{Bad}\left(<3 \mathrm{gl}^{-1}\right)$ & Anthraquinone & Vat & CI Vat Violet 1 (60010) & 0.6900 \\
\hline 24 & Vat Blue RSN & $\operatorname{Bad}\left(<3 \mathrm{gl}^{-1}\right)$ & Anthraquinone & Vat & CI Vat Blue 4 (69800) & 0.7100 \\
\hline 25 & Sulfur Brilliant Green GB & $\operatorname{Bad}\left(<3 \mathrm{gl}^{-1}\right)$ & Sulfide & Sulfur & CI Sulfur Green 3 (53570) & 0.7325 \\
\hline 26 & Vat Dark Blue VB & $\operatorname{Bad}\left(<3 \mathrm{gl}^{-1}\right)$ & Anthraquinone & Vat & & 0.7442 \\
\hline 27 & Cationic Brilliant Blue 2RL & Good $\left(3-30 \mathrm{gl}^{-1}\right)$ & Single-azo & Cationic & CI Basic Blue 54 (11052) & 0.7520 \\
\hline 28 & Vat Blue BO & Good $\left(3-30 \mathrm{gl}^{-1}\right)$ & Anthraquinone & Vat & CI Vat Blue $20(59800)$ & 0.7857 \\
\hline 29 & Reactive Turquoise Blue K-GL & Excellent $\left(>30 \mathrm{gl}^{-1}\right)$ & Phthalocyanine & Reactive & CI Reactive Blue 14 & 0.8945 \\
\hline
\end{tabular}

${ }^{\mathrm{a}} \mathrm{TOC} /$ color: removal ratio of TOC/removal ratio of color. 


\subsection{Operation}

Electrolysis was conducted at $15 \mathrm{~V}$ d.c. The initial dye concentration was $60 \mathrm{mg}^{-1}$. Solutions contained $0.05 \mathrm{moll}^{-1} \mathrm{Na}_{2} \mathrm{SO}_{4}$ as an electrolyte. Volume electric current density was conducted at $0.11 \mathrm{Al}^{-1}$. Solution $\mathrm{pH}$ fluctuated but stayed close to 7 for the various dyes, but the variation is in $\mathrm{pH}$ was normally less than 1 . During 80 min of electrolysis, TOC and color of the solution were measured using the total organic carbon analyzer and Du-650 spectrophotometer, respectively. Each dye was tested three times and the average of the maximum color removal was reported.

\section{Results and discussion}

\subsection{Electrolytic reduction results for the 29 dyes}

The serial numbers, chemical structures, types and CI no. of all dyes used in this work are shown in Table 1. The dyes were numbered from 1 to 29 and included eight types of dye: acid, reactive, neutral, direct, sulfur, cationic, vat and dispersed; and six chemical structures: azo, triaryl methane, anthraquinone, sulfide, heterocyclic and phthalocyanine. TOC/color is the ratio of the removal ratio of TOC to the removal ratio of color, which is a useful index that will be discussed later.

Fig. 1 shows the removal ratio of color and TOC for the 29 dyes utilized in this work. This ACF electrolysis process can successfully decolorize all the tested dyes despite the variety of chemical structure and type. The color removal ratio of solution is uniformly above $85 \%$. But the TOC removal ratio ranged widely, from 30 to $70 \%$. The TOC removal ratio of vat dye and dispersed dye was higher than that of acid dyes, reactive dyes and neutral dyes. It has been shown in by previous work [22] that degradation and adsorption coexist in this system, but act differently in the treatment of various dyes. Combined with the TOC/color values in Table 1, it can be seen that the higher the TOC/color value of a dye, the more important is the adsorption effect involved in its removal. From dye 1 to dye 29,

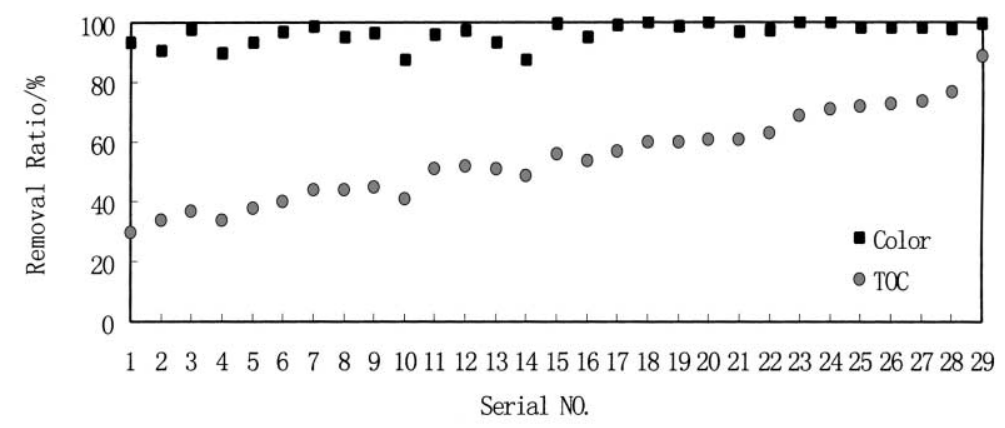

Initial concentration $60 \mathrm{mg} / \mathrm{L}$, after 80 minutes electrolysis, volume electric current density $0.11 \mathrm{~A} / \mathrm{L}, \mathrm{D} . \mathrm{C}, 15 \mathrm{~V}$

Fig. 1. Results of electrochemical treatment of 29 dyes. 
Table 2

Results of electrolysis of dye groups of various solubilities

\begin{tabular}{lll}
\hline Solubility & TOC/color $^{\mathrm{a}}$ & Serial number \\
\hline Excellent $\left(>30 \mathrm{~g}^{-1}\right)$ & $0.4963 \pm 0.1372$ & $1,2,3,5,6,7,8,9,10,12,13,14,16,19,29$ \\
Good $\left(3-30 \mathrm{~g}^{-1}\right)$ & $0.6170 \pm 0.1455$ & $4,17,18,20,27,28$ \\
Bad $\left(<3 \mathrm{~g}^{-1}\right)$ & $0.6558 \pm 0.07821$ & $11,15,21,22,23,24,25,26$ \\
Average & $0.5653 \pm 0.1421$ & \\
\hline
\end{tabular}

a TOC/color: removal ratio of TOC/removal ratio of color.

it has been shown that degradation impacts gradually decrease while adsorption impacts gradually increase.

What is the major factor leading to the different mechanism functions among their various types, chemical structures, and other properties? To find the internal relationship between treatment mechanisms and the dye characteristics, dyes were grouped according to their types, chemical structures and solubility. Their TOC/color value was used to evaluate this mechanism.

Values of TOC/color and dye groups with different solubility are given in Table 2. In brief, the table makes clear that solubility greatly affects the removal mechanism. Dyes with low solubility can be adsorbed easily by ACF or by colloid particles. Their TOC/color value reached 0.65 uniformly, with a small standard deviation. However, very soluble dyes can be degraded more easily in light of their small TOC/color value. Dyes with good solubility have a TOC/color value between these of the other two groups and also have a corresponding relationship between solubility and mechanism function.

As solubility differences are also attributed to different dye chemical structures, it is reasonable to further analyze relations between mechanism function and dye type and chemical structure. Table 3 contains data on the TOC/color value of dye groups with different type and chemical structure.

Acid dyes have $-\mathrm{SO}_{3}{ }^{-},-\mathrm{OH}$, hydrophilic groups. Reactive dyes have $-\mathrm{SO}_{3}{ }^{-},-\mathrm{COO}^{-}$, $-\mathrm{OH}$ groups. Neutral dyes have $-\mathrm{SO}_{2} \mathrm{NH}_{2},-\mathrm{OH}$ groups. These dyes have high solubility and they are not prone to be adsorbed. In this system, their azo linkages are predominantly reduced and yield lower molecular weight aromatic compounds that may be more susceptible to biological aerobic oxidation [22]. There is still much TOC left in their solutions. Their triaryl methane linkages also seem to be reduced or oxidized. However, the oxidation mechanism is not clear. Their anthraquinone linkages are expressly not as easily degraded as their azo linkages, but easier than the linkages in vat dyes. This result is similar to that determined by Karunratne and Lemley [22]. As for reactive turquoise Blue K-GL (29), though it has $-\mathrm{SO}_{2} \mathrm{NH}_{2}$ and $\mathrm{SO}_{3}{ }^{-}$groups and excellent solubility, it has a stable chemical structure with phthalocyanine chelate of copper. It has a tendency to aggregate by hydrogenous bond or chelation. So adsorption and aggregation are predominant in its removal. It has the highest TOC/color value among the dyes.

Vat, dispersed and sulfur dyes are often of azo, anthraquinone and sulfide structures. They have many $-\mathrm{C}=\mathrm{O},-\mathrm{NH}-$ and aromatic groups, hydrophobic ones, and lack $-\mathrm{SO}_{3}{ }^{-},-\mathrm{OH}$ and other hydrophilic groups. Therefore, they tend to be adsorbed by $\mathrm{Fe}(\mathrm{OH})_{x}$ particles and have high TOC/color values. 
Table 3

Results of electrolysis of dye groups of various types and chemical structures

\begin{tabular}{|c|c|c|c|c|c|c|c|c|}
\hline & Acid & Reactive & Neutral & Direct & Sulfur & Cationic & Vat & Disperse \\
\hline Azo & $\begin{array}{l}0.4018 \\
\pm \\
0.09140 \\
(1,2,3,12)\end{array}$ & $\begin{array}{l}0.4391 \\
\pm \\
0.08597 \\
(4,9,13,16)\end{array}$ & $\begin{array}{l}0.4073 \\
(5)\end{array}$ & $\begin{array}{l}0.5409 \\
\pm \\
0.1111 \\
(6,18,20)\end{array}$ & & 0.752 & (27) & $\begin{array}{l}0.6462 \\
(22)\end{array}$ \\
\hline $\begin{array}{l}\text { Triaryl } \\
\text { methane }\end{array}$ & $\begin{array}{l}0.4570 \\
\pm \\
0.01648 \\
(7,10)\end{array}$ & & & & & & & \\
\hline Anthraquinone & $\begin{array}{l}0.4632 \\
(8)\end{array}$ & $\begin{array}{l}0.6073 \\
(19)\end{array}$ & & & & & $\begin{array}{l}0.68707 \\
\pm \\
0.0805 \\
(15,21,23,24,26 \\
28)\end{array}$ & \\
\hline Sulfide & & & & & $\begin{array}{l}0.7520 \\
\pm \\
0.1423 \\
(11,25)\end{array}$ & & & \\
\hline Heterocyclic & & & & & & $\begin{array}{l}0.5682 \\
\pm \\
0.01153 \\
(14,17)\end{array}$ & & \\
\hline Phthalocyanine & & $\begin{array}{l}0.8944 \\
(29)\end{array}$ & & & & & & \\
\hline
\end{tabular}

${ }^{\mathrm{a}}$ Number in the parentheses indicates the serial number.

Direct dyes have $-\mathrm{SO}_{3}{ }^{-},-\mathrm{COOH}$ and $-\mathrm{OH}$ groups and excellent solubility. Their molecules linearly spread in solution and have a tendency to aggregate by hydrogenous bonding of $-\mathrm{OH},-\mathrm{SO}_{3} \mathrm{H}$ and $-\mathrm{COOH}$. They often form colloids in solution and tend to be adsorbed and flocculated. So their azo dyes have a larger TOC/color than acid or reactive azo ones.

Cationic dyes are a complex family. They are mostly made of azo, heterocyclic and anthraquinone structures and dissociate into anions and cations in solution. There are large differences among their removal ratio.

In all, there are some specific relationships between treatment mechanisms and properties of dyes. To answer this complicated question definitively, much work needs to be done. This work can be extended to other treatment process, such as biological systems, coagulation systems and photocatalysis systems. Also other pollutants can be evaluated, i.e. PCBs, PAHs, etc. If a database of treatment methods, pollutants and their effectively were formatted, it could guide the selection of optimal methods of treatment.

\subsection{Typical dynamic electrolysis}

Figs. 2-4 show typical electrolysis of dye Acid Red B (1), Vat Blue BO (28) and Disperse Red E-4B (22). In Fig. 3, there is a linear relationship $\left(r^{2}=0.96\right)$ between color removal ratio and electrolysis time, i.e. there is a linear relationship $\left(r^{2}=0.97\right)$ between TOC 


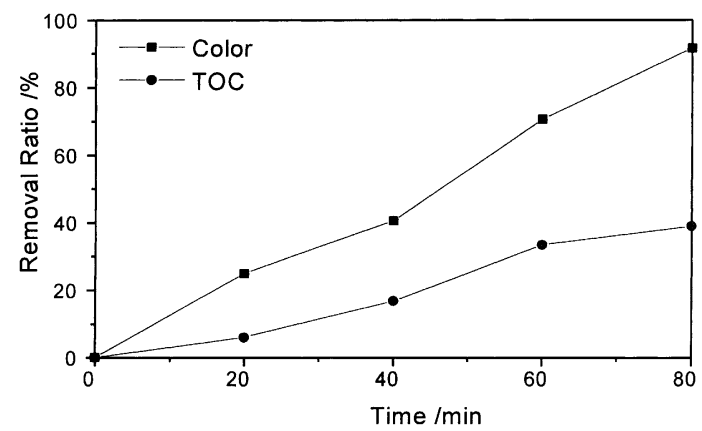

Initial concentration $60 \mathrm{mg} / \mathrm{L}$, volume electric current density $0.11 \mathrm{~A} / \mathrm{L}$, D.C. $15 \mathrm{~V}$

Fig. 2. Typical electrolysis result of dye Acid Red B.

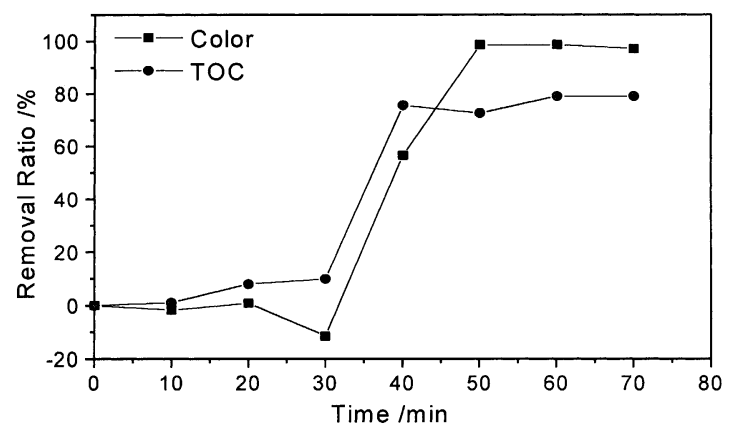

Initial concentration $60 \mathrm{mg} / \mathrm{L}$, volume electric current density $0.11 \mathrm{~A} / \mathrm{L}$, D.C. $15 \mathrm{~V}$

Fig. 3. Typical electrolysis result of dye Vat Blue BO.

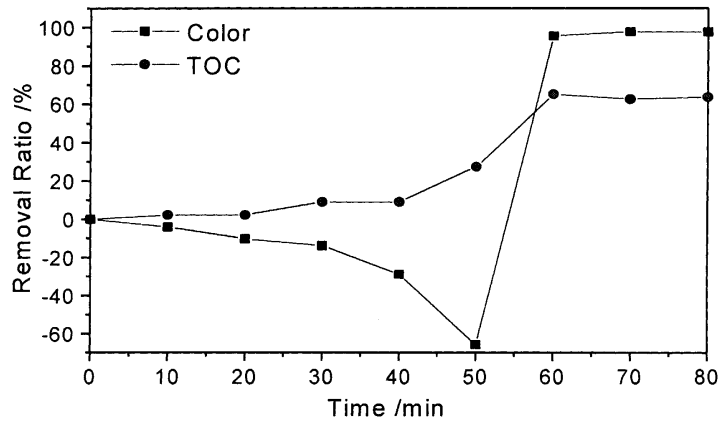

Initial concentration $60 \mathrm{mg} / \mathrm{L}$, volume electric current density $0.11 \mathrm{~A} / \mathrm{L}$, D.C. $15 \mathrm{~V}$

Fig. 4. Typical electrolysis result of dye Disperse Red E-4B. 
Table 4

Correlation coefficients $\left(r^{2}\right)$ of linear equations between removal ratio and time of three typical dyes

\begin{tabular}{lll}
\hline Dye & $r^{2}$ of color removal & $r^{2}$ of TOC removal \\
\hline Acid Red B & 0.96 & 0.97 \\
Vat Blue BO & 0.73 & 0.80 \\
Disperse Red E-4B & 0.33 & 0.86 \\
\hline
\end{tabular}

removal ratio and electrolysis time. Since it has azo groups, it is postulated that the removal dye Acid Red B is most probably due to breakdown of dye molecule through reduction of azo linkage. Its azo linkage is reduced at the cathode in competition with reduction of water. As the ACF cathode does not reduce water, this system is advantageous for the decomposition of dye molecules. Its catalytic activity has been proved in reduction of $\mathrm{NO}$ to $\mathrm{N}_{2}[16,17]$. This reduction occurs evenly during the entire course of treatment. Besides, adsorption on ACF, this soluble dye equilibrates slowly. Therefore, removal ratio curves are almost straight lines.

However, there are two zigzag removal ratio curves in Fig. 3. One line shows that color slightly increases firstly and than decreases drastically. The other line indicates a similar TOC removal course. It is postulated the removal of Vat Blue BO is accomplished mainly by adsorption and coagulation. On the basis of Faraday's law, we conclude that the ferrous iron generated is proportional to the current and the time. In this system, ferrous hydroxide is generated at a rate of $3.1 \mathrm{mg} \mathrm{l}^{-1} \mathrm{~min}^{-1}$. Ferrous hydroxide turns into ferric hydroxide via oxidation in solution. Both ferrous hydroxide and ferric hydroxide can form colloid, adsorb dye molecule and coagulate in water. This process yields deeper color. Simultaneously, these particles and dye can also be adsorbed by ACF. This adsorption aggregates the particles close to or on ACF, which in turn may accelerate colloid precipitation. After $93 \mathrm{mg}$ of ferrous hydroxide are generated $(30 \mathrm{~min})$, colloid precipitation occurs: the precipitation usually can be observed visually. TOC and color are quickly removed with the precipitation, which is responsible for the shape of curves in Fig. 3.

Fig. 4, shows that electrolysis of dye Disperse Red E-4B is similar to that of dye Vat Blue BO. A non-linear relationship is found for both dyes in the plot of removal versus time: this finding is confirmed in Table 4. Additionally, colloid precipitation occurs at $50 \mathrm{~min}$ in Fig. 4, 20 min later than in Fig. 3. Adsorption and coagulation are also the predominate mechanisms in removal of this dispersed dye, which probably is due to its poor solubility.

The dynamic electrolysis of dye Acid Red B, Vat Blue BO and Disperse Red E-4B shows how the two major mechanisms, degradation and adsorption, work differently in the removal process. To some extent, this result confirms that of Karunaratne and Lemley [22], whose previous work has shown that both degradation and adsorption are involved in color removal with azo dyes and that adsorption is the predominant mechanism of dye removal with anthroquinones dyes.

\section{Conclusions}

The degradation of 29 dyes by means of an ACF electrode electrolysis system was performed successfully. Almost all the tested dye solutions were decolorized effectively in this ACF electrolysis process. 
The internal relationship between treatment mechanisms and characters of dye has been discussed. Above all, it is clear that the higher solubility a dye has, the more important the degradation effect is involved in its removal.

There are certain relationships between treatment mechanisms and properties of dyes. Acid, reactive and neutral dyes have many $-\mathrm{SO}_{3}{ }^{-}, \mathrm{COO}^{-},-\mathrm{SO}_{2} \mathrm{NH}_{2},-\mathrm{OH}$, hydrophilic groups. Their azo linkages are susceptible the reduction. While vat, dispersed and sulfur dyes are often made of azo, anthraquinone and sulfide structures, they have many $-\mathrm{C}=\mathrm{O},-\mathrm{NH}-$ and aromatic groups. These dyes tend to be adsorbed by $\mathrm{Fe}(\mathrm{OH})_{x}$ particles. Direct dyes have $-\mathrm{SO}_{3}{ }^{-},-\mathrm{COOH}$ and $-\mathrm{OH}$ groups and excellent solubility. Their molecules linearly spread in solution and have a significant tendency to aggregate by hydrogenous bonding. They often form colloids in solution and also tend to be adsorbed and flocculated.

The dynamic electrolysis of dye Acid Red B, Vat Blue BO and Disperse Red E-4B shows the different functions of the two major mechanisms, degradation and adsorption, during the entire course of treatment. The reduction occurs uniformly. However, in the course of dominant adsorption process, after certain iron is produced, colloid precipitation occurs and TOC and color are quickly removed in this period.

\section{Acknowledgements}

The authors acknowledge the financial support of Chinese National Natural Science foundation (29637010).

\section{References}

[1] J. Naumczyk, L. Szpyrkowicz, F. Zilio Grandi, Water Sci. Technol. 33 (1996) 17.

[2] A.G. Vlyssides, M. Loizidou, P.K. Karlis, A.A. Zorpas, D. Papaioannou, J. Hazard. Mater. 70 (1999) 41.

[3] Y. Yoshida, S. Ogata, S. Nakamatsu, T. Shimamune, K. Kikawa, H. Inoue, C. Iwakura, Electrochem. Acta 45 (1999) 409.

[4] J. Rodgers, W. Jedral, N. Bunce, Environ. Sci. Technol. 33 (1999) 1453.

[5] E. Brillas, E. Mur, R. Sauleda, L. Sanchez, J. Peral, X. Domenech, J. Casado, Appl. Catal. B 16 (1998) 31.

[6] M. Nicola, T. Badea, Sci. Technol. Environ. Prot. 3 (1996) 3.

[7] S. Lchikawa, N. Komagai, class:ICM:c02f001-461. JP 09103787, Japan, 1997.

[8] M. Tezuka, M. Jwasaki, in: Proceedings of the 3rd Asia-Pacific Conference Plasma Science Technology, Japan Society for the Promotion of Science, Local Organizing Committee of APCPST', Tokyo, Japan, 1996, pp. 423-427.

[9] M. Takashi, class:ICM:c02f001-461. JP 10174975, Japan, 1998.

[10] K. Shizuo, The Chem. Soc. Jpn. 6 (1993) 694.

[11] C. Pelekani, V.L. Snoeyink, Water Res. 33 (1999) 1209.

[12] P. Lee, J. Davidson, Am. Ind. Hyg. Assoc. J. 60 (1999) 589.

[13] J. Li, Z. Yu, M. Gao, X. Cai, Water Air, Soil Pollut. 97 (1997) 367.

[14] H. Yoshida, S. Fukuda, A. Okamoto, T. Kataoka, Water Sci. Technol. 23 (1991) 1667.

[15] M. Uchida, T. Nakamura, N. Kawasaki, S. Kitayama, S. Tanada, Toxicol. Environ. Chem. 63 (1997) 227.

[16] I. Mochida, S. Kawano, S. Kisamori, H. Fujitsu, T. Maeda, Carbon 32 (1994) 175.

[17] J. Imai, K. Kaneko, J. Coll. Interf. Sci. 148 (1992) 595-597.

[18] E. Exprosito, A. Saez, E. Herrero, A. Aldaz, Water Environ. Res. 70 (1998) 306.

[19] M. Okochi, T.-K. Lim, N. Nakamura, T. Matsunaga, Appl. Microbiol. Biotechnol. 47 (1997) 18.

[20] T. Matsunaga, S. Nakasono, Y. Kitajima, K. Horiguchi, Biotechnol. Bioeng. 43 (1994) 429.

[21] J. Jia, J. Yang, J. Liao, W. Wang, Z. Wang, Water Res. 33 (1999) 881.

[22] S.A. Karunaratne, A.T. Lemley, J. Envirn. Sci. Health Pt A 34 (1999) 217. 